\title{
ECCR1 and NFKB2 Polymorphisms as Potential Biomarkers of Non-small Cell Lung Cancer in a Polish Population
}

\author{
MONIKA CHASZCZEWSKA-MARKOWSKA ${ }^{1}$, MONIKA KOSACKA ${ }^{2}$, AGNIESZKA CHRYPLEWICZ ${ }^{1}$, \\ TOMASZ DYŁA ${ }^{2}$, ANNA BRZECKA ${ }^{2}$ and KATARZYNA BOGUNIA-KUBIK ${ }^{1}$ \\ ${ }^{1}$ Laboratory of Clinical Immunogenetics and Pharmacogenetics, \\ Hirszfeld Institute of Immunology and Experimental Therapy, Polish Academy of Sciences, Wroclaw, Poland; \\ ${ }^{2}$ Chair and Department of Pulmonology and Lung Cancer Wroclaw Medical University, Wroclaw, Poland
}

\begin{abstract}
Background/Aim: Although genetic factors are presumed to account only for a part of the inter-individual variation in lung cancer susceptibility, the results are conflicting and there are no data available regarding the Polish population. We, therefore, performed a case-control study to investigate the association of seven selected single nucleotide polymorphisms (SNPs), in genes coding for excision repair cross-complimentary group 1 (ERCC1: rs11615, rs3212986, rs2298881), nuclear factor $k B$ (NFKB2: rs7897947, rs12769316), bone morphogenetic protein 4 (BMP4: rs1957860), complement receptor 1 (CR1: rs7525160) and del/ins polymorphism in the family hypoxia inducible factor 2 gene (EGLN2: rs10680577), with non-small cell lung cancer (NSCLC) risk. Materials and Methods: Real-time PCR with melting curve analysis was used for genotyping of NSCLC patients and healthy individuals of Polish origin. Results: The ERCC1 rs11615 T allele and rs3212986 GG homozygosity were found to be associated with a higher risk of developing NSCLC. In addition, NFKB2 rs 12769316 GG homozygosity was more frequently detected among male patients than controls, while no significant differences were found between the five polymorphisms. Conclusion: ERCC1 polymorphisms may affect NSCLC risk in the Polish population, while the NFKB2 variant may be a possible marker of the disease in males.
\end{abstract}

Lung cancer is the leading cause of cancer-related death worldwide. In Poland, lung cancer is the leading cause of cancer among men and the third most common malignancy

Correspondence to: Dr. Monika Chaszczewska-Markowska, Laboratory of Clinical Immunogenetics and Pharmacogenetics, Hirszfeld Institute of Immunology and Experimental Therapy, Polish Academy of Sciences, R. Weigla 12, 53-114 Wroclaw, Poland. Tel: +48 713371172, e-mail: monika.chaszczewska@iitd.pan.wroc.pl

Key Words: Non-small cell lung cancer, genetic predisposition, single nucleotide polymorphism, ECCR1, NFkB2. after breast and colon cancer among women (1). Non-small cell lung cancer (NSCLC) accounts for the vast majority of all lung cancer cases. Despite intensive progress in understanding, prevention and treatment of NSCLC, the prognosis is still poor. The 5-year survival rates for regional and metastatic NSCLC are about 30\% and 5\%, respectively (2). Although tobacco use and environmental factors are presumed to be the prevalent risk factors contributing to lung cancer development, susceptibility to NSCLC might be at least in part attributed to interindividual genetic variability (3).

Genetic alterations in DNA repair genes, such as $X P F$, ERCC2, XRCCl, and hOGGl, are associated with an increased risk of developing lung cancer and emphasize the significance of the defective DNA-damage response in the disease development $(4,5)$. Nucleotide excision repair pathway (NER) plays a vital role in protecting the genome against various endogenous and exogenous mutagens and is considered to be the most versatile DNA repair pathway that counteracts the widest range of DNA lesions and damages. The excision repair cross-complimentary group 1 (ERCCI) gene is one of the most crucial DNA repair genes and codes for a subunit of the NER complex-ERCC1-XPF that acts as a structure-specific endonuclease to catalyze the 5 ' incision of the DNA lesion (6). Due to the significance of ERCC1 as an essential NER pathway protein, playing a critical role in genomic stability maintenance, it is believed that inherited functional polymorphisms in ERCC1 may contribute to the attenuated capacity to repair DNA damage, and thus enhance the susceptibility to cancer (7).

Previous studies have investigated the association between SNPs in the ERCCl gene and increased risk of developing several kinds of cancers in many different populations. However, the results were inconclusive (8-11) and so far, no report has been published regarding lung cancer-associated ERCC1 variants in the Polish population.

Inflammation, infection and chronic irritation are critical events of cell transformation (12). Carcinogens and inflammatory cytokines contributing substantially to cancer 
development are involved in the activation of common cell survival signaling pathways. One of these cell survival signalling pathways involve nuclear factor-kappaB (NF-kB), which is involved in multiple steps in carcinogenesis and in cancer cell resistance to chemo- and radiotherapy (13). NF-kB is a transcription factor which is known to affect the expression of more than 150 genes related to inflammation, lymphocyte activation, cell proliferation, differentiation, and apoptosis, as well as contributing to cell apoptosis and survival. Recently, many studies with animal models and cell culture systems have indicated the interplay between NF-kB and lung carcinogenesis, which emphasizes the importance of targeting the NF-kB signaling pathway for lung cancer treatment and chemoprevention (14). To the best of our knowledge, there is no report about the impact of polymorphisms within the NF$\mathrm{kB}$ gene on lung cancer risk in the Polish population.

Molecular epidemiological studies have shown that lung cancer is associated with single nucleotide polymorphisms (SNPs), therefore we selected eight polymorphisms (including 7 SNPs) for which no data are available regarding the Polish population. The following genes were analysed: ERCC1 (5 SNPs), two in NFKB2 (2 SNPs), coding for bone morphogenetic protein 4 (BMP4, one SNP), complement receptor 1 (CR1, one SNP) and family hypoxia inducible factor 2 ( $E G L N 2$, ins/del polymorphism).

\section{Materials and Methods}

Study groups. In this study we evaluated eight polymorphisms, three SNPs in the ERCC1 gene (rs11615 synonymous substitution C>T, rs3212986 downstream variant $\mathrm{G}>\mathrm{T}$, rs2298881 intron variant A $>$ C), two SNPs in the NFKB2 gene (rs7897947 intron variant $\mathrm{T}>\mathrm{G}$, rs12769316 upstream variant $\mathrm{A}>\mathrm{G}$ ), one in the $B M P 4$ (rs1957860 intron variant $\mathrm{C}>\mathrm{T}$ ), one in the $C R 1$ gene (rs7525160 upstream variant $\mathrm{G}>\mathrm{C}$ ) and an intronic del/ins polymorphism in the EGLN2 gene (rs10680577, -/TACT/TTAC).

Eighty-four primary NSCLC patients $(\mathrm{F} / \mathrm{M}=24 / 60)$ were genotyped for the rs11615, rs3212986, rs 1957860, rs7525160 SNPs and 146 patients $(\mathrm{F} / \mathrm{M}=48 / 98)$ for rs7897947, rs12769316, rs10680577, rs2298881 polymorphisms. NSCLC patients were recruited from the Chair and Department of Pulmonology and Lung Cancer Wroclaw Medical University, Poland. All the patients were newly diagnosed, without a history of prior radiotherapy and/or chemotherapy and confirmed with histopathological examination. The exclusion criteria included primary extra-pulmonary malignancy, small cell lung cancer, a history of malignant disease, withdrawal of consent and patient aged less than 18 years.

In addition, 234 healthy subjects that served as the control group were recruited from the Regional Centre of Transfusion Medicine and Blood Bank in Wroclaw. All participants signed an informed consent before enrollment and Institutional Ethical committee approval was obtained for the study.

DNA extraction and genotyping. Genomic DNA was extracted from EDTA-anticoagulated peripheral blood using innuPREP Blood DNA Master Kit (Analityk Jena, Jena, Germany) according to the manufacturer's recommendations and stored at $-20^{\circ} \mathrm{C}$ until required.
Genotyping was performed by the LightSNiP typing assay (TIBMolBiol, Berlin, Germany) on a LightCycler 480 Real-Time PCR system (Roche Diagnostics, Rotkreuz, Switzerland) following manufacturer's instructions.

Statistical analysis. All statistical analyses, including the HardyWeinberg equilibrium (HWE) test and the association of genotypes and haplotypes with NSCLC development, were conducted using GraphPad Prism (GraphPad Software, Inc. La Jolla, CA, USA) for Windows. HWE and between-groups comparison of genotype distribution were analysed using Pearson's goodness-of-fit chisquared test. To assess the effect of each polymorphism on NSCLC, risk odds ratios (OR) and corresponding 95\% confidence intervals (CI) were calculated. All $p$-values were calculated with two-sided Fisher's exact test and $p<0.05$ was considered to be statistically significant.

\section{Results and Discussion}

Numerous data have shown that SNP variants could be implicated in the development of various cancer types (15, 16). In this study, three out of eight selected polymorphisms were found to affect the risk for the development of NSCLC in our Polish patients.

Frequencies of all polymorphisms were in accordance with the Hardy-Weinberg equilibrium in both patient and control groups $(p>0.05)$. No linkage disequilibrium was found between these loci.

The ERCC1 rs $11615 \mathrm{~T}$ allele $(\mathrm{OR}=3.40, p=0.018$, 95\% CI=1.104-11.68) and the rs3212986 GG homozygosity ( $\mathrm{OR}=1.905, p=0.021,95 \% \mathrm{CI}=1.093-3.334)$ were found to be associated with predisposition to NSCLC (Figure 1). Moreover, the NFKB2 rs12769316 GG homozygosity was more frequently detected among male patients than controls ( $p=0.035$, Figure 2). No significant differences were found in the allele and genotype distributions for the five other polymorphisms.

The same two SNPs within the ECCR1 gene, rs11615 and rs3212986, were also investigated by Gao et al. in Chinese patients. Their results showed that both gene polymorphisms appeared to act as predictive factors for tumour response to chemotherapy and clinical outcome of advanced NSCLC (17). They observed that individuals carrying the rs 11615 $T T$ genotype and $T$ allele or carriers of the rs3212986 AA genotype and $A$ allele, had a significantly lower response rate to chemotherapy. Moreover, these genetic variants were also significantly associated with increased risk of mortality from NSCLC.

The NFKB2 rs12769316 was identified in our study as a marker of NSCLC predisposition in males. The role of this SNP has also been studied in haematological malignancies, especially in bortezomib-based treatment of patients with multiple myeloma (MM). Du et al. reported a superior overall survival for patients with the NFKB2 rs12769316 GA+AA genotype. However, they did not observe any 

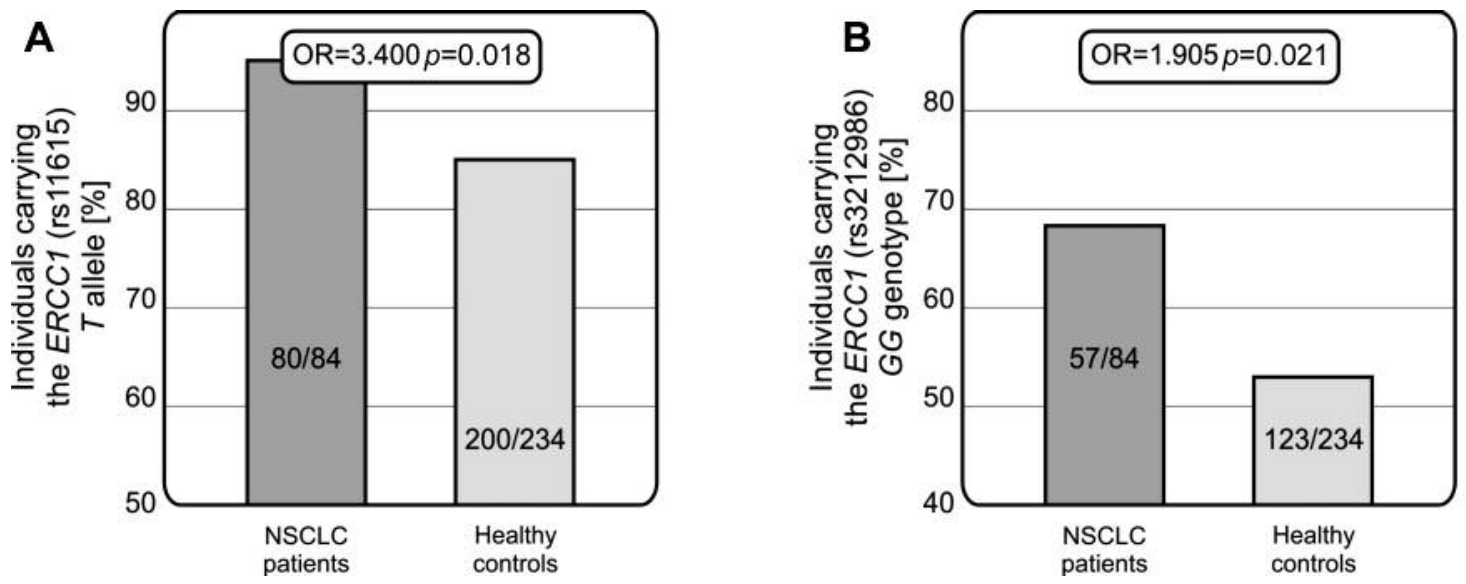

Figure 1. Associations of the ERCC1 rs11615 and rs3212986 polymorphisms with NSCLC.

association of the NFKB2 rs12769316 variants with MM susceptibility (18). Very recently, this SNP was found to be significantly associated with NSCLC risk and overall survival in Greek patients (19).

The limitations of our study need to be addressed. This study was a single-centre cohort investigation of a relatively small scale. To the best of our knowledge, the polymorphisms studied have not been previously explored in the Polish population. In conclusion, the results of our study involving Polish patients with NSCLC indicate that the ERCC1 rs11615 and rs3212986 polymorphisms may act as genetic markers associated with predisposition to the disease, while the $N F k B 2$ rs12769316 SNP can affect disease development in males.

\section{Conflicts of Interest}

The Authors have declared no conflicting interests.

\section{Acknowledgements}

This study was financed by Wroclaw Medical University-Statutory Activity no 935: "The evaluation of selected genes polymorphisms in non-small cell lung cancer and their relationship with course of neoplasma disease".

\section{Authors' Contributions}

MC-M: conceived and designed the experiments, performed the experiments, drafted the manuscript; MK: contributed with patients recruitment, diagnosis and clinical assessment; AC: performed the experiments, analysed the data; TD: participated in collection of clinical data and patients' material; $\mathrm{AB}$ : supervised recruitment of patients, collection of clinical data and patients' material; KB-K: supervised immunogenetic studies, contributed to preparation of the manuscript and revised its final version.

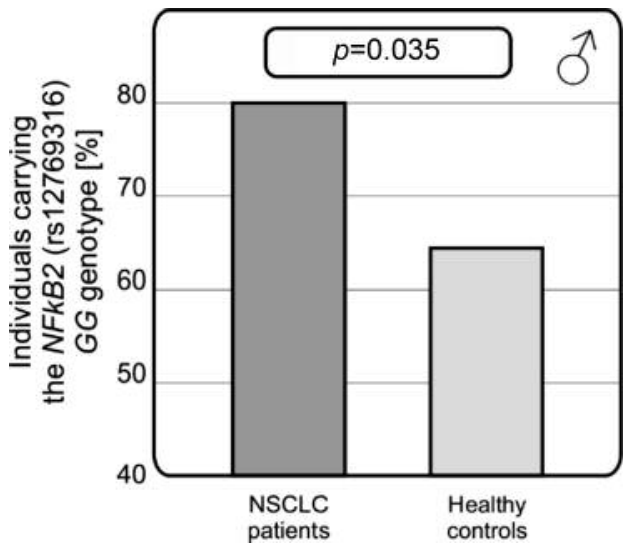

Figure 2. Distribution of the NFKB2 GG homozygosity among NSCLC male patients and healthy men.

\section{References}

1 Didkowska J, Wojciechowska U and Zatoński W: Nowotwory złośliwe w Polsce w 2014 roku. Cent Onkol Warszawa, 2016.

2 Howlader N, Noone AM, Krapcho M, Miller D, Bishop K, Kosary CL, Yu M, Ruhl J, Tatalovich Z, Mariotto A, Lewis DR, Chen HS, Feuer EJ and Cronin KA (eds.): SEER Cancer Statistics Review, 1975-2014, National Cancer Institute. Bethesda, MD, USA, 2016. Available at: https://seer.cancer.gov/csr/1975_2014/

3 Cruz CS, Tanoue LT and Matthay RA: Lung cancer: epidemiology, etiology, and prevention. Clin Chest Med 32: 605644, 2011. PMID: 22054876. DOI: 10.1016/j.ccm.2011.09.001

4 Olaussen KA, Dunant A, Fouret P, Brambilla E, André F, Haddad V, Taranchon E,Filipits M, Pirker R, Popper HH, Stahel R, Sabatier L, Pignon JP, Tursz T, Le Chevalier T and Soria JC; IALT Bio Investigators: DNA repair by ERCC1 in non-smallcell lung cancer and cisplatin-based adjuvant chemotherapy. $\mathrm{N}$ Engl J Med 355: 983-991, 2006. PMID: 16957145. DOI: 10.1056/NEJMoa060570 
5 Sugimura H, Kohno T, Wakai K, Nagura K, Genka K, Igarashi H, Morris BJ, Baba S, Ohno Y, Gao C, Li Z, Wang J, Takezaki T, Tajima K, Varga T, Sawaguchi T, Lum JK, Martinson JJ, Tsugane S, Iwamasa T, Shinmura K and Yokota J: hOGG1 Ser326Cys polymorphism and lung cancer susceptibility. Cancer Epidemiol Biomarkers Prev 8: 669-674, 1999. PMID: 10744126.

6 Marteijn JA, Lans H, Vermeulen W and Hoeijmakers JH: Understanding nucleotide excision repair and its roles in cancer and ageing. Nat Rev Mol Cell Biol 15: 465-481, 2014. PMID: 24954209. DOI: $10.1038 / \mathrm{nrm} 3822$

7 Zhang L, Wang J, Xu L, Zhou J, Guan X, Jiang F, Wu Y and Fan $\mathrm{W}$ : Nucleotide excision repair gene ERCC1 polymorphisms contribute to cancer susceptibility: A meta-analysis. Mutagenesis 27: 67-76, 2012. PMID: 22002622. DOI: 10.1093/mutage/ ger062

8 Ni M, Zhang WZ, Qiu JR, Liu F, Li M, Zhang YJ, Liu Q and Bai J: Association of ERCC1 and ERCC2 polymorphisms with colorectal cancer risk in a Chinese population. Sci Rep 4: 4112, 2014. PMID: 24531312. DOI: 10.1038/srep04112

9 Xu H, Feng Y, Jia Z, Yang J, Lu X, Li J, Xia M, Wu C, Zhang Y and Chen J: Association between ERCC1 rs3212986 and ERCC2 rs13181 gene polymorphisms in NER pathway and the risk of bladder cancer in a Chinese population. Int J Clin Exp Pathol 9: 2295-2300, 2016. PMID: 27051038. DOI: 10.4238/gmr.15017879

10 Zhu J, Hua RX, Jiang J, Zhao LQ, Sun X, Luan J, Lang Y, Sun Y, Shang K, Peng S and Ma J: Association studies of ERCC1 polymorphisms with lung cancer susceptibility: A systematic review and meta-analysis. PLoS One 19: e97616, 2014. PMID: 24841208. DOI: 10.1371/journal.pone.0097616

11 Chen WH, Xin PL, Pan QX, Chen YY, Wang CR, Zhang ZS, Chen YF, Zhang CY and Cai WJ: ERCC1 single nucleotide polymorphism C8092A, but not its expression is associated with survival of esophageal squamous cell carcinoma patients from Fujian province, China. PloS One 9: e106600, 2014. PMID: 25191856. DOI: 10.1371 /journal.pone. 0106600

12 Coussen LM and Werb Z: Inflammation and cancer. Nature 420: 860-866, 2002. PMID: 12490959. DOI: 10.1038/nature01322

13 Koti M, Gooding RJ, Nuin P, Haslehurst A, Crane C, Weberpals J, Childs T,Bryson P, Dharsee M, Evans K, Feilotter HE, Park $\mathrm{PC}$ and Squire JA: Identification of the IGF1/PI3K/NFkB/ERK gene signalling networks associated with chemotherapy resistance and treatment response in high-grade serous epithelial ovarian cancer. BMC Cancer 13: 549, 2013. PMID: 24237932. DOI: $10.1186 / 1471-2407-13-549$
14 Chen W, Li Z, Bai L and Lin Y: NF-kappaB in lung cancer, a carcinogenesis mediator and a prevention and therapy target. Front Biosci 16: 1172-1185, 2011. PMID: 21196225.

15 Formica V, Doldo E, Antonetti FR, Nardecchia A, Ferroni P, Riondino S, Morelli C, Arkenau HT, Guadagni F, Orlandi A and Roselli M: Biological and predictive role of ERCC1 polymorphisms in cancer. Crit Rev Oncol Hematol 111: 133-143, 2017. PMID: 28259288. DOI: 10.1016/j.critrevonc.2017.01.016

16 Benna C, Helfrich-Förster C, Rajendran S, Monticelli H, Pilati P, Nitti D and Mocellin S: Genetic variation of clock genes and cancer risk: A field synopsis and meta-analysis. Oncotarget 8: 2397823995, 2017. PMID: 28177907. DOI: 10.18632/ oncotarget.15074

17 Gao H, Ge RC, Liu HY, Wang Y and Yan S: Effect of ERCC1 polymorphism on the response to chemotherapy and clinical outcome of non-small cell lung cancer. Genet Mol Res 13: 89979004, 2014. PMID: 25366790. DOI: 10.4238/2014. October. 31.14

18 Du J, Huo J, Shi J, Yuan Z, Zhang Ch, Fu W, Jiang H, Yi Q and Hou J: Polymorphisms of nuclear factor- $\mathrm{kB}$ family genes are associated with development of multiple myeloma and treatment outcome in patients receiving bortezomib-based regimens. Haematologica 96: 729-737, 2011. PMID: 21228035. DOI: 10.3324/haematol.2010.030577

19 Dimitrakopoulos FD, Antonacopoulou AG, Kottorou AE, Maroussi S, Panagopoulos N, Koukourikou I, Scopa C, Kalofonou M, Koutras A, Makatsoris T, Papadaki H, Dougenis $\mathrm{D}$, Brock $\mathrm{M}$ and Kalofonos HP: NF-kB2 genetic variations are significantly associated with non-small cell lung cancer risk and overall survival. Sci Rep 8: 5259, 2018. PMID: 29588475. DOI: $10.1038 / \mathrm{s} 41598-018-23324-3$ 